Jensen (Copenhagen). Prof. G. S. Avery (New London, U.S.A.) makes a plea for the consideration of the auxins as protoplasm irritants or 'evoca. tors'. Prof. Bouillenne (Liège) discusses the action of auxins on cell division and root formation, and expresses the rather surprising opinion that although promotion of cambial division and inhibition of lateral bud development occur on applying pure auxins, at concentrations within the physiological range, to a variety of plants, nevertheless "under natural conditions" the auxins do not have these effects. Finally, Mlle. Zollikofer (Zurich) reviews the rather unsatisfactory state of the work on the effect of animal hormones on plant growth. It seems unfortunate that Prof. Nðmeč, who (according to the preface) proposed the conference, and who has long been active in the closely related field of regeneration, should not have been present.

As is natural in a field which is developing so rapidly, there are many matters of dispute, and most of the papers stress points of uncertainty rather than the well-established facts. The very extensive material presented, however, makes clear how impressive has been the progress in the last few years towards an understanding of the control of growth in plants. Perhaps the most interesting parts of the book are the discussions, which are reported in full. Naturally a conversation between half a dozen men who are really familiar with the field is of much greater value than the usual questions at a large meeting.

The fact that many substances, which are probably not present in plant tissues, have physiological effects almost indistinguishable from those of the naturally occurring auxins, raised much discussion. Animal hormones present parallel cases. The difficulty centred partly on nomenclature, and partly on the applicability of results obtained with these synthetic substances to the interpretation of natural processes. As to the former, an agreement was reached according to which two groups of growth substances are distinguished, $(a)$ the auxins, $(b)$ the bios group. The auxins comprise those actually present in plants (phytohormones proper), and those not present but exerting similar effects. The bios group includes aneurin, biotin, œstrin, etc., known to be present in plants, and a group of substances designated 'specific nutrients', such as mesoinositol, $\beta$-alanine, leucine, and pyruvic and gluconic acids. The grouping of these latter under bios, a term which up to now has had a rather specific meaning, seems wholly unjustified, both because 'specific nutrients' are difficult to define and because such a large and heterogeneous group of compounds is involved.

Another question raised was whether the action of auxins constitutes 'irritability' or not. However, this was soon found to be unprofitable for lack of a clear statement of the rather old-fashioned concept of 'irritability' or stimulus, and the related one of stimulus-substances (Reizstoffe).

At the close of the conference, Prof. Boysen Jensen invited the members to meet again in Copenhagen in September 1939. The success of this first venture would seem to justify further extension of these small conferences between specialists in definite fields of scientific activity.

KenNeth V. Thimann.

\title{
Contributions of Engineering to Physics
}

\section{$\mathrm{P}$} ROF. M. L. E. OLIPHANT, of the University of Birmingham, took as the subject of his evening discourse to the British Association, delivered at Cambridge on August 22, the contributions of engineers, more especially electrical engineers, to the science of physics. To cover the whole field in a single lecture would be impossible and so he confined himself to a few only of the technical contributions made by electrical engineers to physics. He began by making a quotation from a dinner speech of Lord Rutherford.

"For the greater part of my life I have been engaged in investigations to try to obtain a clearer idea of the relations between electricity and matter, and the all-important part that electrical charges play in the structure of the atoms of our material world. Yet, I would find it difficult to tell you what electricity is. It is so fundamental an entity in Nature that explanation is impossible. Yet our knowledge of the laws which electricity obeys is now so complete that we are able to predict with considerable confidence the performance of any piece of electrical machinery-provided, of course, it is large compared to the atom."

As Prof. Oliphant was a pupil of Lord Rutherford and naturally the inspiration which he gave to all who worked with him in his famous laboratory has coloured his outlook, he wisely contented himself by illustrating his lecture by examples taken from the Cavendish Laboratory and the work carried out there, going back to the time when sealing-wax and string were practically the only essentials of a piece of apparatus for physical research. Many physicists regret the passing of that direct simplicity of approach. They recognize that the physicist can no longer be self-sufficient. 'The time is therefore ripe for a review of the situation which may help us to see how the interactions of engineering and physics may best be employed to their mutual advancement.

Electrical engineering, by the provision of technical equipment and facilities and by nurturing physical research in its own laboratories, has made the greatest contribution to the advancement of physics. Prof. Oliphant pointed out that when Faraday in 1831 made fundamental experiments on the magnetic induction in an iron ring, he had to make his own insulated conductors by winding laboriously twine and wire together over layers of calico.

Probably the greatest contribution made byelectrical engineering to the physical sciences is the provision of an abundant and steady supply of electricity for laboratory purposes. Prof. Oliphant recalled the time when a small gas engine used to drive a dynamo, and this in turn was used to charge accumulators. The supply of electricity to a class was therefore limited, and the voltage drop made the experiments very difficult. Rutherford used to tell of the trouble of preparing each morning a number of Grove cells and how these used often to fail badly in the course of the day's work. In these days also, the only voltmeter in the Cavendish Laboratory was a Cardew hot-wire instrument which was very sluggish in its action and took a large current, so that in measuring the voltage of a small accumulator, great care had to be taken 
to prevent the accumulator being run down completely. Nowadays, ammeters and voltmeters of precision are available at low prices for laboratory work. This is due to the great demand for them by the wireless industry.

When electricians agreed to make alternating current supply the standard, many laboratories found themselves in considerable difficulties, as a steady direct current is needed for many fundamental experiments. Luckily, the copper-oxide rectifier developed by the Westinghouse Company in the United States 'converts' the alternating current into direct current most satisfactorily. These efficient and apparently everlasting little pieces of apparatus have saved physical laboratories large sums of money and have proved of immense help. The copper-oxide rectifier when exposed to light is found to generate an electric current. It is therefore possible to use it in photometry and for measuring the density of photographic blackening.

Prof. Oliphant pointed out how the work of Cockcroft, Lawrence and Kapitza has revolutionized the apparatus required for a physical laboratory. With the help of the Metropolitan-Vickers Electrical Co., Ltd., a 50-cycle 2,000 kw. A.c. generator has been constructed the nominal rating of which is $2,000 \mathrm{kw}$., but when short-circuited for half a cycle develops a power of $55,000 \mathrm{kw}$. Magnetic fields were generated of considerable volume under a magnetic force of 300,000 gauss. Dr. T. E. Allibone's valuable work on the problem of applying high electric potentials to evacuate insulating vessels is of great importance. Before he left the Cavendish Laboratory he had succeeded in producing considerable beams of artificial $\beta$-rays.

Dr. C. R. Burch, of Metropolitan-Vickers, found that it is possible to produce by vacuum distillation of mineral oils, residual oils with very low vapour pressure. These oils can be distilled unchanged in a vacuum of a fraction of a millimetre. The apparatus of Cockcroft and Walton was an unqualified success and with it they showed for the first time that accelerated particles of hydrogen can penetrate the nucleus of certain atoms and produce profound changes in them. This and the discovery of the neutron stimulated research into these problems all over the world.

At the same time that Cockeroft and Walton were developing the high-voltage method for accelerating particles, Prof. E. C. Lawrence of Berkeley, California, was experimenting with indirect methods which do not require large voltages. $\mathrm{He}$ was successful in developing the 'cyclotron', by means of which he accelerated particles to energies corresponding with nine million volts. The cyclotron has proved of immense utility to nuclear research. Unfortunately it is very expensive. The magnets of the cyclotrons at Liverpool and Cambridge weigh 50 tons each, of which seven tons is copper, and they produce a field of 19,000 gauss over a gap $90 \mathrm{~cm}$. in diameter.

The new branches of physies are by far the most fundamental of any as they touch the ultimate constitution of matter itself. They can only be attacked successfully by very highly skilled teams of workers, as the number of pieces of intricate apparatus which has to function simultaneously is very large. New effects are being continually observed, and it is necessary to explain them and correlate them with existing knowledge.

Rutherford and Geiger were able to detect and count for the first time the number of $\alpha$-particles emitted by a gram of radium, but the method has several defects and is exceedingly difficult to apply. The method now used is to amplify the current produced in a small ionization chamber by the pulse of ions due to each $\alpha$-particle. This is heard as a loud click in a speaker attached to the amplifier.

Prof. Oliphant concluded by giving a quotation from Bacon, frequently used by Rutherford : "Human knowledge and human power are coextensive; for ignorance of causes prevents us from producing effects. Nature can only be ruled by being obeyed; for the causes which theory discovers give the rules which practice applies."

\section{Radio Exhibition, Olympia}

$\mathrm{T}$ HE annual exhibition of wireless apparatus organized by the Radio Manufacturers' Association was held at Olympia on August 24 until September 3, and it was notable for such features as the replacement of the B.B.C. Radio Theatre by a glass-walled television studio in operation, the first large display of television receivers in actual operation on exhibitors' stands, and the complete demonstration of sound broadcasting receivers for the first time. On previous occasions the stands were supplied inside the exhibition with audio-frequency programme current, so that no demonstration of the radio frequency portion of receivers could be given. This year, arrangements were made for all stands to be supplied with radio frequency signals so that the various receivers could be demonstrated as a whole.

On the technical side, sound broadcasting receivers appear to have settled down to fairly standard types of design, and with the steady improvement of detail which has resulted in methods of lay-out and manufacture during recent years, the modern receiver is very efficient and supplies the needs of the majority of listeners. The chief novel feature among this year's sets is the incorporation of some form of automatic tuning, by means of which a certain number of broadcasting stations can be selected at will by operating switches on the front of the receiver. To what extent this feature was really required by the listener time will tell, but it would appear to be consistent with the demands of the age and to have advantages comparable with those of the automatic telephone and the pre-selector gear on motor-cars. The automatically tuned receiver is provided with a series of about six push-buttons in addition to the usual on-and-off switch; by pressing one of these buttons, the receiver is automatically adjusted to receive the programme from a certain station. In some cases the actual stations made available to the press-button control can be altered by carrying out certain more or less simple adjustments on the receiver. The manner of achieving this automatic tuning varies among the manufacturers and has called forth a considerable amount of mechanical ingenuity in some cases. The methods vary from the switching in of one of a series of fixed condensers across each tuned circuit of the receiver, to the use 